\title{
INFORMACIONI SISTEM ZA PODRŠKU ODLUČIVANJU NA ŽELEZNICI BAZIRAN NA WCF DATA SERVISIMA
}

\author{
Slađana Janković ${ }^{1}$, Snežana Mladenović ${ }^{1}$, Slavko Vesković ${ }^{1}$, Irina Branović ${ }^{2}$ \\ ${ }^{1}$ Saobraćajni fakultet Univerziteta u Beogradu, \\ ${ }^{2}$ Univerzitet Singidunum, Beograd
}

\begin{abstract}
:
Kako bi odredile optimalan način osiguranja putno-pružnih prelaza Železnice Srbije (ŽS) moraju raspolagati podacima o obimu drumskog saobraćaja na prelazima. U ovom radu razvijen je informacioni sistem (IS) koji ŽS omogućava da preuzimaju potrebne podatke od Javnog preduzeća „Putevi Srbije“ (JPPS) u realnom vremenu. IS se sastoji od Windows aplikacije, Windows Communication Foundation (WCF) Data servisa i SQL baze podataka. Servisi se pozivaju iz Windows aplikacije; oni preuzimaju podatke iz SQL baze podataka JPPS, a zatim se preuzeti podaci prikazuju u istoj Windows aplikaciji.
\end{abstract}

\section{Key words:}

IS za podršku odlučivanju; WCF Data servis; razmena podataka; interoperabilnost

Zahvaljujemo se Ministarstvu prosvete, nauke i tehnološkog razvoja Republike Srbije, koje je podržalo ovaj rad u okviru projekta pod brojem 036012.

\section{UVOD}

Jedan od najznačajnijih zadataka Železnica Srbije (ŽS), kada je u pitanju bezbednost železničkog saobraćaja, jeste da smanji broj saobraćajnih nezgoda na putno-pružnim prelazima. Da bi se donela odluka kod kojih putno-pružnih prelaza je potrebno povećati stepen osiguranja, potrebno je raspolagati podacima o obimu drumskog saobraćaja na prelazima [1]. Brojanje saobraćaja na državnim putevima Republike Srbije vrši Javno preduzeće "Putevi Srbije" (JPPS), uz pomoć automatskih brojača i sistema za naplatu putarine. Stoga Železnice Srbije moraju periodično da preuzimaju podatke o saobraćajnim tokovima od JPPS. U ovom radu predlažemo model za preuzimanje podataka u realnom vremenu uz pomoć Windows Communication Foundation (WCF) Data servisa. WCF Data servisi su posebna vrsta Web servisa koja omogućava pristup različitim udaljenim sistemima za upravljanje bazama podataka, izvršavanje upita nad tim bazama i prikazivanje rezultata upita unutar Windows ili Web aplikacija. U drugoj sekciji rada biće predstavljen Windows Communication Foundation Framework.

U okviru rada razvijen je prototip informacionog sistema (IS), kao deo pilot projekta realizovanog za potrebe Železnica Srbije. Frontalni deo IS predstavlja klijentska Windows aplikacija Putno-pružni prelazi, koja ŽS omogućava upravljanje podacima o putno-pružnim prelazi- ma. Razvijena su i dva WCF Data servisa koji iz Microsoft SQL Server baze podataka JPPS preuzimaju podatke o prosečnom godišnjem i prosečnom mesečnom dnevnom saobraćaju po osnovnim vrstama vozila na saobraćajnim deonicama. WCF Data servisi pozivaju se iz pomenute Windows aplikacije, a podacima koje servisi obezbeđuju može se manipulisati u istoj aplikaciji. Ova Windows aplikacija zajedno sa pomenutim Web servisima i bazama podataka sa kojima komunicira predstavlja informacioni sistem za podršku odlučivanju pri upravljanju putnopružnim prelazima. Informacioni sistem biće detaljno opisan u trećoj sekciji rada.

U zaključnoj sekciji rada biće analizirane mogućnosti WCF Data servisa u razvoju informacionih sistema za podršku odlučivanju.

\section{WINDOWS COMMUNICATION FOUNDATION FRAMEWORK}

Windows Communication Foundation Framework je moćan radni okvir za dizajniranje, razvoj, hostovanje i korišćenje servisa. Budući da su razvijeni na Microsoftovoj platformi, WCF servisi mogu da koriste standardne tehnologije da bi obezbedili širok spektar sposobnosti koje se tiču: sigurnosti, transakcija i komunikacije [2]. Pre nego što su se pojavili WCF servisi .NET programeri, 
koji su razvijali distribuirane aplikacije, morali su da biraju između komunikacionih šema kao što su: ASP.NET Web servisi, .NET remoting i MSMQ (Microsoft Message Queuing). Taj izbor implicirao je izbor načina projektovanja, razvoja i korišćenja komponenti. Ako je izabrao ASP. NET Web servise, programer se istovremeno opredelio i za XML format poruka i pomirio sa ograničenjima HTTP (Hypertext Transfer Protocol) protokola. Ako je izbor pao na .NET remoting, programer može da računa na efikasno procesuiranje poruka, ali istovremeno mora da se pomiri sa činjenicom da klijenti servisa mogu biti isključivo .NET klijenti. MSMQ je veoma moćan kada su u pitanju diskonektovane aplikacije, ali njegovim izborom eliminiše se bilo kakva mogućnost uspostavljanja sinhrone, requestresponse konverzacije sa klijentskim softverom.

U osnovi, WCF je radni okvir za slanje poruka između sistema. To nije distribuirani, na komponentana zasnovan radni okvir, poput remoting-a ili DCOM-a (Distributed Component Object Model). Kada se koriste WCF servisi razmenjuju se request i response poruke. Cilj WCF radnog okvira je da objedini ovih nekoliko tehnologija i obezbedi jedinstvenu, u odnosu na transport neutralnu, razvojnu paradigmu sa zajedničkim pogledom na pitanja sigurnosti, transakcija i obrade izuzetaka [3]. Servisi se implementiraju nezavisno od strategije vezane za komunikacioni protokol. Ovo je revolucionaran koncept koji dizajnerima servisa obezbeđuje fleksibilnost. Umesto izgradnje servisa sa čvrsto povezanim i krutim endpoint-ima, kod kojih promene nisu dobrodošle, omogućeno je projektovanje fleksibilnih servisa.

WCF Data servisi su elegantna Microsoft-ova tehnologija za objavljivanje podataka, bilo iz baza podataka sa lokalnih servera ili iz baza podataka iz oblaka. Mogu se hostovati na lokalnim Web serverima ili na serverima iz oblaka. WCF Data servise mogu koristiti kako Windows tako i Web aplikacije. Aplikacija koja koristi WCF Data servis može biti desktop aplikacija, Web aplikacija hostovana na lokalnom Web serveru, ili Web aplikacija hostovana kao servis u oblaku. Način korišćenja WCF Data servisa ne zavisi od vrste aplikacije koja ga poziva, već od toga kakva mu je namena. Microsoft je obezbedio više modela podataka, koji se mogu izložiti kao WCF Data servisi:

- ADO.Net Entity Data Model,

- LINQ to SQL Classes,

- Custom Data Model (Object, XML, itd).

\section{IS ZA PODRŠKU ODLUČIVANJU NA ŽELEZNICI}

\section{Faze u razvoju informacionog sistema}

U upravljanju bezbednošću železničkog i drumskog saobraćaja jedan od najznačajnijih zadataka je da se podigne nivo bezbednosti saobraćaja na pružnim prelazima [4]. Da bi se identifikovali prelazi na kojima je potrebno intervenisati, bilo u smislu promene načina osiguranja, ili u smislu rekonstrukcije i održavanja drumske i železničke infrastruktre, potrebno je raspolagati mnogobrojnim podacima, koji se mogu razvrstati u tri kategorije:
- podaci o trenutnom stanju pružnih prelaza: lokacija prelaza sa aspekta pruge (stanično područje ili otvorena pruga) i sa aspekta puta (magistralni, regionalni ili lokalni put), postojeći način osiguranja prelaza, postojeće stanje drumske i železničke signalizacije u zoni prelaza, vrstu i stanje prekrivača kolovoza na prelazu, bankine i sistemi za odvodnjavanje u zoni prelaza, geometrijski parametri prelaza, trougao preglednosti i daljine vidljivosti, (ne)postojanje mogućnosti denivelacije, propisane brzine kretanja vozova i drumskih vozila u zoni prelaza;

- podaci o saobraćajnim nezgodama na prelazima u nekom izabranom periodu: ukupan broj nezgoda, struktura nezgoda prema posledicama, ukupan broj lakše povređenih, teže povređenih i poginulih lica, ukupna materijalna šteta;

- podaci o obimu i strukturi drumskog i železničkog saobraćaja na prelazima.

Za potrebe upravljanja putno-pružnim prelazima na ŽS, u okviru pilot projekta, razvijen je prototip informacionog sistema, koji bi trebalo da predstavlja podršku u odlučivanju. Odlučivanje se pre svega odnosi na izdvajanje pružnih prelaza kod kojih je potrebno intervenisati i definisanje potrebnog načina intervenisanja na identifikovanim pružnim prelazima. Takvo odlučivanje potrebno je obaviti na nekoliko godina, a po potrebi i češće. Najznačajniji deo tog IS predstavlja prototip Windows aplikacije Putno-pružni prelazi. Aplikacija ima dve osnovne namene. Prvo, treba da omogući zaposlenima na Železnicama Srbije da pretražuju i ažuriraju sopstvenu bazu podataka o pružnim prelazima. U bazi se skladište podaci o: trenutnom stanju pružnih prelaza, obimu i strukturi železničkog saobraćaja na prelazima i saobraćajnim nezgodama koje su se na njima dogodile.

Podaci koji ŽS nedostaju odnose se na obim i strukturu drumskog saobraćaja na prelazima. Brojanje drumskog saobraćaja vrši JPPS uz pomoć automatskih brojača, a podatke dobijene sa brojača skladišti na svom serveru, u Microsoft SQL Server bazi podataka. To ŽS nameće potrebu da periodično preuzimaju podatke o obimu drumskog saobraćaja od JPPS. JPPS tražene podatke može da obezbedi u formi .pdf datoteka i odštampane na papiru. Tako dobijeni podaci ne mogu se pretraživati niti na bilo koji način koristiti bez dodatne obrade, što posao čini komplikovanijim, a donošenje odluka o osiguranju pružnih prelaza sporijim. Da bi se preuzimanje podataka učinilo efikasnijim i pouzdanijim, definisan je drugi važan zadatak aplikacije. On se sastoji u tome da aplikacija omogući automatizovano, $\mathrm{u}$ realnom vremenu, preuzimanje podataka o obimu drumskog saobraćaja od JPPS. Iz tog razloga, informacioni sistem za podršku odlučivanju na železnici proširen je razvojem WCF Data servisa, koji imaju zadatak da preuzimaju potrebne podatke iz SQL Server baze podataka JPPS. Aplikacija dobija podatke pozivom odgovarajućih metoda WCF Data servisa i omogućava njihovo prikazivanje, sortiranje, grupisanje i pretraživanje.

Na Sl. 1 prikazane su faze razvoja IS za podršku odlučivanju na Železnicama Srbije. U prvoj fazi razvijena je Windows aplikacija Putno-pružni prelazi. Za potrebe pre- 
uzimanja podataka iz Microsoft SQL Server baze podataka JPPS Brojanje saobraćaja kreirana su dva ADO.Net Entity Data modela podataka koji su izloženi kao WCF Data servisi. WCF Data servisi hostovani su na lokalnom Web serveru ŽS. U aplikaciju Putno-pružni prelazi dodate su reference na WCF Data servise, kako bi iz aplikacije bilo moguće pozivanje metoda ovih servisa. Iz aplikacije se pozivaju metode WCF Data servisa, koje dobavljaju podatke iz baze podataka JPPS.

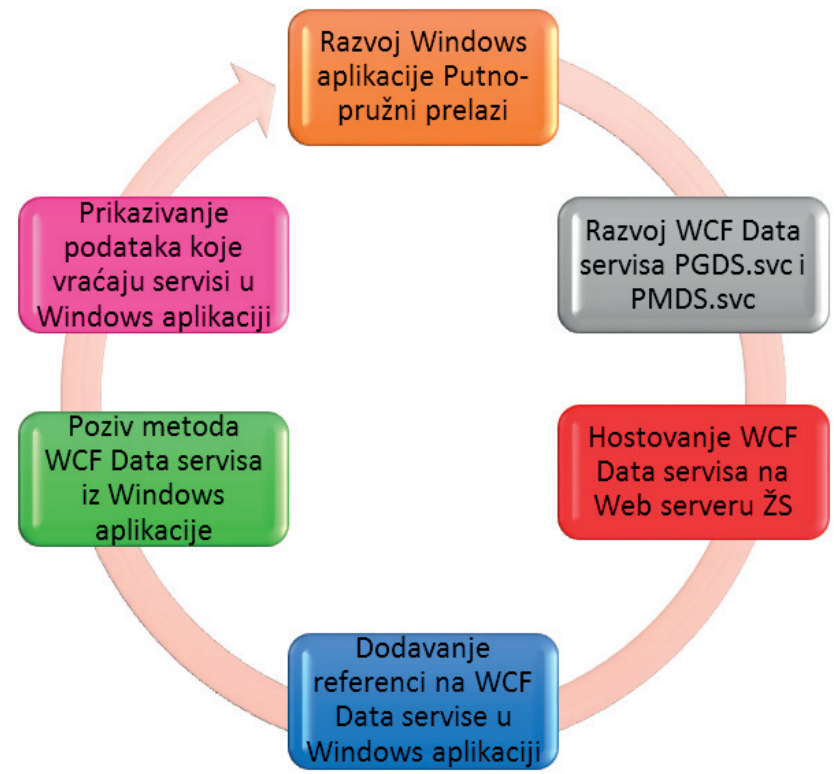

Sl. 1. Faze u razvoju IS za podršku odlučivanju na Železnicama Srbije

Dobijeni podaci prikazuju se unutar prozora Windows aplikacije. Da bi aplikacija omogućila i razne vrste ma- nipulisanja dobijenim podacima (sortiranja, filtriranja, grupisanja, pretraživanja), poslednja faza u razvoju IS je nadogradnja Windows aplikacije, čiji je razvoj započeo u prvoj fazi.

\section{Windows aplikacija Putno-pružni prelazi}

U ovoj sekciji biće prikazan deo aplikacije koji preuzima i prikazuje podatke o obimu i strukturi drumskog saobraćaja na pružnim prelazima. Na Sl. 2 prikazan je prozor Prosečan godišnji dnevni saobraćaj na deonicama puteva iz aplikacije Putno-pružni prelazi unutar koga se prikazuju podaci o obimu drumskog saobraćaja na deonicama puteva, za izabrani put i izabranu godinu. Gornja tabela prikazuje prosečan godišnji dnevni saobraćaj - PGDS, ukupno i po osnovnim kategorijama vozila. Podaci iz gornje tabele prikazani su na dijagramu. Deonice puteva sortirane su prema PGDS-u, u opadajućem poretku, tako da se lako uočavaju najopterećenije deonice. Za svaku deonicu, u istom prozoru, moguće je proveriti da li na njoj ima pružnih prelaza. Izborom oznake deonice u gornjoj tabeli generišu se redovi u donjoj tabeli - podaci o prelazima, ukoliko na izabranoj deonici ima prelaza. Na Sl. 2, u gornjoj tabeli izabrana je deonica puta Negotin-Veljkovo, čija je oznaka 0291, a u donjoj tabeli prikazani su podaci o dva putno-pružna prelaza koji se nalaze na toj deonici puta. Podaci o obimu i strukturi drumskog saobraćaja, na jednom izabranom pružnom prelazu, po godinama, mogu se videti u prozoru aplikacije prikazanom na Sl. 3. Na Sl. 3 može se uočiti da je na pružnom prelazu sa oznakom 01/M 24 obim drumskog saobraćaja, iz godine u godinu u porastu, a da se struktura drumskog saobraćaja nije bitnije menjala.

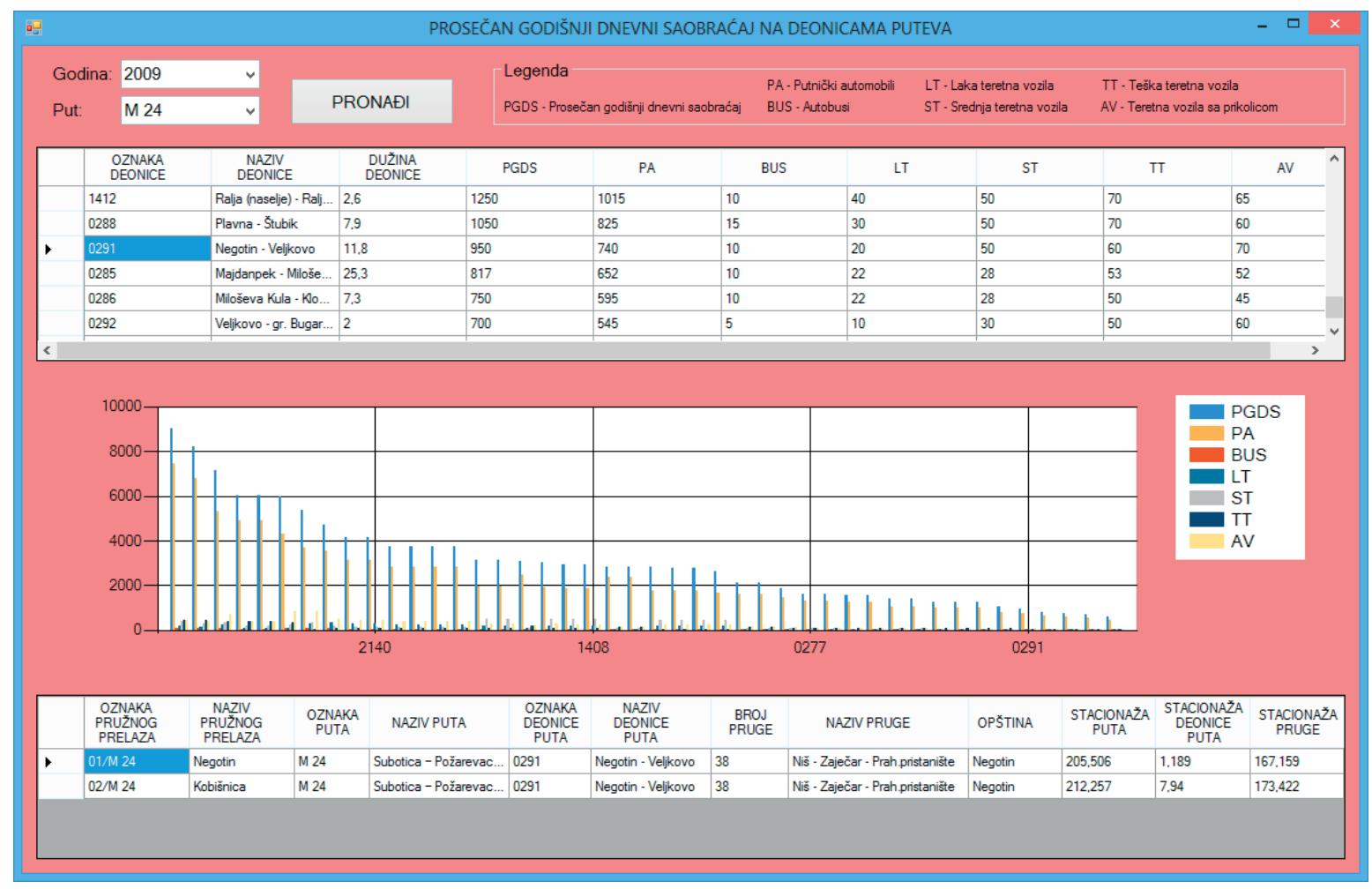

Sl. 2. Prozor Prosečan godišnji dnevni saobraćaj na deonicama puteva iz aplikacije Putno-pružni prelaz 


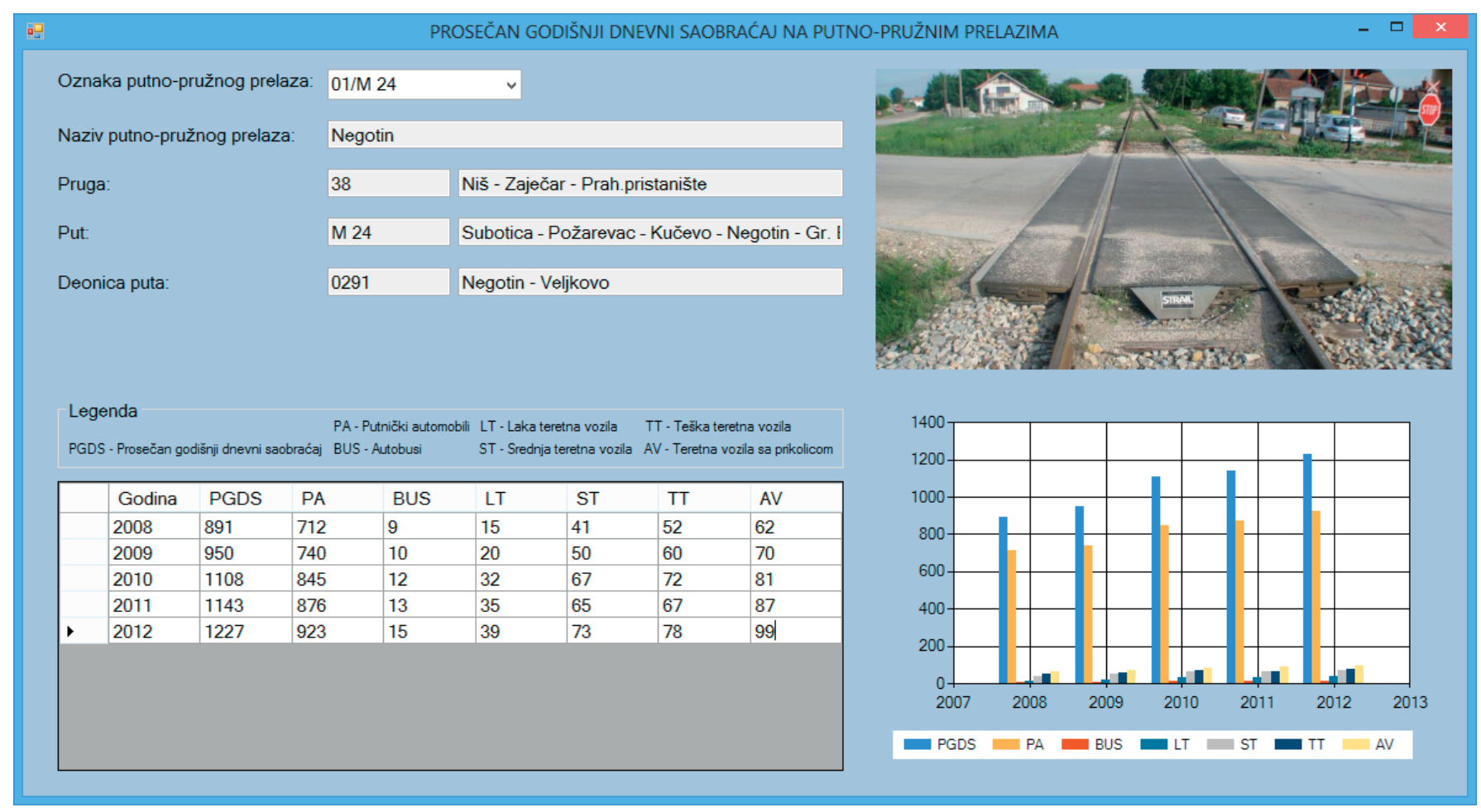

Sl. 3. Prozor Prosečan godišnji dnevni saobraćaj na putno-pružnim prelazima iz aplikacije Putno-pružni prelazi

\section{WCF Data servisi PGDS.svc i PMDS.svc}

Windows aplikacija Putno-pružni prelazi ima zadatak da iz SQL Server baze podataka JPPS preuzme dve kategorije podataka o obimu i strukturi drumskog saobraćaja. Prvu kategoriju podataka predstavlja PGDS - prosečan broj drumskih vozila na deonicama puteva, na dnevnom nivou, pri čemu se prosek pravi za jednu kalendarsku godinu. Drugu kategoriju podataka predstavlja PMDS prosečan broj drumskih vozila na deonicama puteva, na dnevnom nivou, pri čemu se prosek pravi za svaki mesec u jednoj kalendarskoj godini. Svaku kategoriju podataka čine podaci o ukupnom broju vozila i podaci o broju vozila po osnovnim kategorijama: putnički automobili, autobusi, laka teretna vozila, srednja teretna vozila, teška teretna vozila i teretna vozila sa prikolicama. Za obe kategorije podataka razvijen je po jedan ADO.Net Entity Data model podataka koji je izložen kao WCF Data servis.

Model podataka Godisnji_obim_saobracajaEntities omogućava preuzimanje podataka o PGDS i izložen je kao WCF Data servis PGDS.svc. Model podataka Mesecni_ obim_saobracajaEntities omogućava preuzimanje podataka o PMDS i izložen je kao WCF Data servis PMDS. $s v c$. Svaki model podataka kreiran je nad odgovarajućom tabelom SQL Server baze podataka JPPS i omogućava preuzimanje svih podataka iz te tabele. Oba servisa trebalo bi da budu hostovana na Web serveru Železnica Srbije. Zatim su klijentskoj aplikaciji Putno-pružni prelazi dodate reference na ova dva servisa, što je omogućilo pozivanje njihovih metoda iz procedura događaja aplikacije i prikazivanje podataka u klijentskoj aplikaciji Putno-pružni prelazi.

\section{ZAKLJUČAK}

Svedoci smo činjenice da je razmena informacija postala imperativ u savremenom poslovanju [5]. Ovaj rad imao je za cilj da demonstrira upotrebu jedne napredne vrste Web servisa u svrhu razmene podataka na nivou informacionih sistema. Realizacijom pilot projekta u oblasti železničkog saobraćaja ustanovili smo da ova vrsta Web servisa omogućava jednostavnu, jeftinu, automatizovanu razmenu podataka u realnom vremenu. Stoga možemo da zaključimo da WCF Data servisi mogu predstavljati pouzdan oslonac u razvoju informacionih servisa za podršku odlučivanju.

\section{Zahvalnice}

Ovaj rad delimično je podržan od strane Ministarstva prosvete, nauke i tehnološkog razvoja Republike Srbije, u okviru projekta pod brojem 036012.

\section{LITERATURA}

[1] S. Verstichel, et al., "Efficient data integration in the railway domain through an ontology-based methodology," Transportation Research Part C, Vol. 19, No. 4, 2011, pp. 617643.

[2] Seroter, R., E. Fairweather, S. W. Thomas, M. Sexton, and R. Ramani (2010), Applied Architecture Patterns on the Microsoft Platform, Packt Publishing, Birmingham

[3] Sharp, J. (2010), Windows ${ }^{\oplus}$ Communication Foundation 4 Step by Step, O’Reilly Media, Inc., Sebastopol 
[4] S. Janković, S. Mladenović, et al., "Integration PlatformAs-A-Service In The Traffic Safety Area," MIC-CNIT2011, Mosharaka International Conference on Communications, Networking and Information Technology, Dubai, UAE, Dec. 16-18. 2011, pp. 70-75.

[5] Janković, S. (2013), B2B integracija saobraćajnih sistema, Zadužbina Andrejević, Beograd

\section{INFORMATION SYSTEM FOR DECISION SUPPORT AT RAILWAYS BASED ON WCF DATA SERVICES}

\section{Abstract:}

To determine the optimal way of ensuring railroad crossings Serbian Railways (SR) must have data on the volume of road traffic at crossings. In this paper we developed an information system (IS), which allows SR to take the necessary information from the Public Enterprise "Roads of Serbia" (PERS) in real time. IS consists of Windows application, Windows Communication Foundation (WCF) Data Services and SQL database. Services are invoked from Windows application, they take data from SQL database of PERS, and then downloaded data displays in the same Windows application.

\section{Key words:}

IS for Decision Support, WCF Data Service, Data Exchange, Interoperability. 